\title{
$\mu$-Phenolato- $\mu$-azido-bridged Dinuclear Zinc(II) Complex with a Schiff-base Having Imidazolyl Groups
}

\author{
Masahiro Mikuriya, ${ }^{\dagger}$ Ai Shibutani, Hitomi Yamada, and Daisuke Yoshioka \\ Department of Applied Chemistry for Environment and Research Center for Coordination Molecule-based Devices, \\ School of Science and Technology, Kwansei Gakuin University, 2-1 Gakuen, Sanda 669-1337, Japan
}

\begin{abstract}
A $\mu$-phenolato- $\mu$-azido-bridged dinuclear zinc(II) complex with 2,6-bis( $N$-(4-imidazolylethyl)iminomethyl)-4methylphenol (Hbimmp), $\left[\mathrm{Zn}_{2}(\right.$ bimmp $\left.)\left(\mu-\mathrm{N}_{3}\right)\left(\mathrm{N}_{3}\right)(\mathrm{Cl})\right]$, was synthesized. The crystal structure was determined by a single-crystal X-ray diffraction method at $293 \mathrm{~K}$. The complex crystallizes in the monoclinic space group $P 2{ }_{1} / c$ with $a=9.2278(10), b=26.069(3), c=10.0068(11) \AA, \beta=93.261(2)^{\circ}, V=2403.4(4) \AA^{3}, D_{\mathrm{x}}=1.657 \mathrm{~g} / \mathrm{cm}^{3}, Z=4$. The $R 1$ $[I>2 \sigma(I)]$ and $w R 2$ (all data) values are 0.0342 and 0.0892 , respectively, for all 5717 independent reflections. The two zinc(II) atoms are bridged by a phenolato-oxygen of bimmp ${ }^{-}$and a $\mu$-azido-nitrogen atom, where each zinc(II) atom is further coordinated by imino- and imidazolyl-nitrogen atoms of bimmp ${ }^{-}$and azido-nitrogen and chlorido atoms with half occupation to form a square-pyramidal or trigonal-bipyramidal geometry.
\end{abstract}

(Received June 12, 2018; Accepted July 6, 2018; Published on web August 10, 2018)

A Schiff-base ligand, 2,6-bis(N-(4-imidazolylethyl)iminomethyl)4-methylphenol (Hbimmp), is an interesting dinucleating ligand, because it has imidazolyl groups. Zinc complexes with this ligand can be expected to have some relevance to active centers in biological systems, such as carboxypeptidases, leucine aminopeptidases, and alkaline phosphatases, where imidazole groups are bound to zinc ions. ${ }^{1}$ So far, dinuclear copper, ${ }^{2-4}$ tetranuclear manganese,${ }^{5}$ and pentanuclear iron ${ }^{6}$ complexes with the bimmp ${ }^{-}$ligand were reported. In this study, we isolated a dinuclear zinc(II) complex with bimmp ${ }^{-}$, and determined the crystal structure of this complex, which shows a dinuclear core with $\mu$-phenolato- $\mu$-azido bridges, as shown in Fig. 1. This paper describes the synthesis and crystal structure of $\left[\mathrm{Zn}_{2}(\right.$ bimmp $\left.)\left(\mu-\mathrm{N}_{3}\right)\left(\mathrm{N}_{3}\right)(\mathrm{Cl})\right]$.

The complex was prepared by a template reaction of 2,6-diformyl-4-methylphenol (Hdfmp) ${ }^{7}$ and histamine in the presence of zinc(II) salt and sodium azide in methanol. Hdfmp (8.4 $\mathrm{mg}, 0.05 \mathrm{mmol})$ and histamine dihydrochloride $(18.2 \mathrm{mg}$,

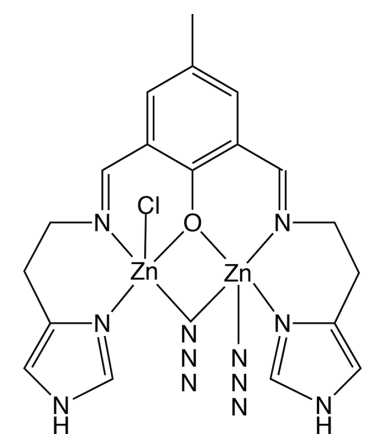

Fig. 1 Chemical structure of $\left[\mathrm{Zn}_{2}(\right.$ bimmp $\left.)\left(\mu-\mathrm{N}_{3}\right)\left(\mathrm{N}_{3}\right)(\mathrm{Cl})\right]$.

\footnotetext{
† To whom correspondence should be addressed.
}

E-mail: junpei@kwansei.ac.jp
$0.1 \mathrm{mmol})$ were dissolved in $12 \mathrm{~cm}^{3}$ of methanol. Then, triethylamine ( $15.8 \mathrm{mg}, 0.15 \mathrm{mmol})$, zinc(II) nitrate hexahydrate (29.9 $\mathrm{mg}, 0.1 \mathrm{mmol}$ ), and sodium azide $(14.4 \mathrm{mg}, 0.22 \mathrm{mmol})$ were successively added. The reaction mixture was stirred for a while, and then filtered. The resulting yellow filtrate was left

Table 1 Crystal and experimental data

Chemical formula: $\mathrm{C}_{19} \mathrm{H}_{21} \mathrm{ClN}_{12} \mathrm{OZn}$

Formula weight $=599.67$

$T=293 \mathrm{~K}$

Crystal system: monoclinic

Space group: $P 2_{1} / c$

$a=9.2278(10) \AA$

$b=26.069(3) \AA$

$c=10.0068(11) \AA$

$\beta=93.261(2)^{\circ}$

$V=2403.4(4) \AA^{3}$

$Z=4$

$D_{\mathrm{x}}=1.657 \mathrm{~g} / \mathrm{cm}^{3}$

Radiation: Mo $K \alpha(\lambda=0.71073 \AA)$

$\mu($ Mo $K \alpha)=2.147 \mathrm{~mm}^{-1}$

$F\left(\begin{array}{lll}0 & 0 & 0)=1216\end{array}\right.$

Crystal size $=0.50 \times 0.39 \times 0.23 \mathrm{~mm}^{3}$

No. of reflections collected $=15138$

No. of independent reflections $=5717$

$\theta$ range for data collection: 2.183 to $28.495^{\circ}$

Data/Restraints/Parameters $=5717 / 0 / 353$

Goodness-of-fit on $F^{2}=1.037$

$R$ indices $[I>2 \sigma(I)]: R 1=0.0342, w R 2=0.0553$

$R$ indices (all data): $R 1=0.0827, w R 2=0.0892$

$(\Delta / \sigma)_{\max }=0.002$

$(\Delta \rho)_{\max }=0.375 \mathrm{e}^{-3}$

$(\Delta \rho)_{\min }=-0.263 \mathrm{e}^{-3}$

Measurement: Bruker Smart APEX CCD diffractometer

Program system: SHELXTL

Structure determination: intrinsic phasing (SHELXT-2014/4)

Refinement: full matrix least-squares (SHELXL-2014/7)

CCDC deposition number: 1845621 


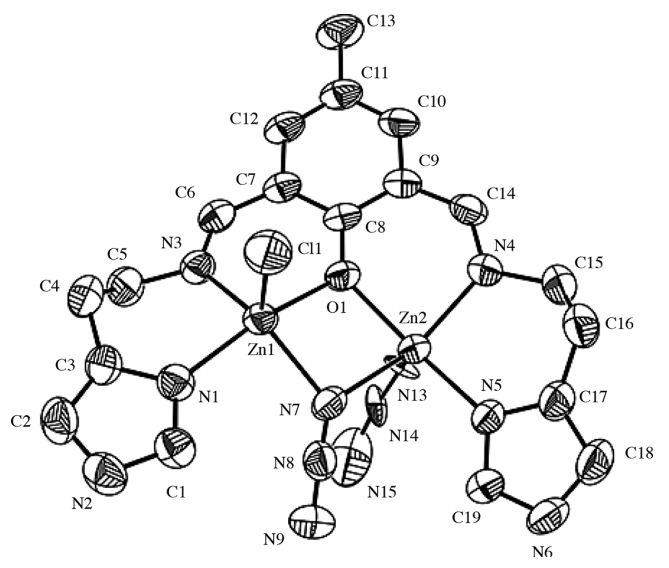

Fig. 2 ORTEP drawing of $\left[\mathrm{Zn}_{2}(\right.$ bimmp $\left.)\left(\mu-\mathrm{N}_{3}\right)\left(\mathrm{N}_{3}\right)(\mathrm{Cl})\right]$, showing the thermal ellipsoids at the $50 \%$ probability level. One of the disordered atoms, $\mathrm{N}_{3}$ and $\mathrm{Cl}$, are omitted for clarity.

Table 2 Selected bond distances $(\AA)$ and angles $\left({ }^{\circ}\right)$

\begin{tabular}{lcll}
\hline Zn1--Zn2 & $3.3313(5)$ & Zn2-O1 & $2.0316(17)$ \\
Zn1-O1 & $2.1018(17)$ & Zn2-N4 & $2.099(2)$ \\
Zn1-N1 & $2.090(2)$ & Zn2-N5 & $2.058(2)$ \\
Zn1-N3 & $2.071(2)$ & Zn2-N7 & $2.217(2)$ \\
Zn1-N7 & $2.097(2)$ & Zn2-N13 & $1.999(15)$ \\
Zn1-N10 & $1.986(10)$ & Zn2-C12 & $2.300(3)$ \\
Zn1-Cl1 & $2.355(3)$ & & \\
Zn1-O1-Zn2 & $107.39(7)$ & Zn1-N7-Zn2 & $101.06(9)$ \\
\hline
\end{tabular}

Table 3 Hydrogen-bonding geometry $\left(\AA,^{\circ}\right)$

\begin{tabular}{|c|c|c|c|c|}
\hline D-H...A & D-H $(\AA)$ & H...A $(\AA)$ & D...A $(\AA)$ & $\mathrm{D}-\mathrm{H} \cdots \mathrm{A}\left({ }^{\circ}\right)$ \\
\hline $\mathrm{N} 2-\mathrm{H} 2 \mathrm{~B} \cdots \mathrm{Cl} 2^{\mathrm{i}}$ & 0.86 & 2.31 & $3.166(4)$ & 172.3 \\
\hline $\mathrm{N} 2-\mathrm{H} 2 \mathrm{~B} \cdot \cdots \mathrm{N} 13^{\mathrm{i}}$ & 0.86 & 2.05 & $2.903(14)$ & 169.3 \\
\hline N6-H6B $\cdots \mathrm{Cl1}^{\mathrm{ii}}$ & 0.86 & 2.40 & $3.163(6)$ & 148.2 \\
\hline N6-H6B $\cdots$ N10 & 0.86 & 2.27 & $3.086(11)$ & 159.3 \\
\hline
\end{tabular}

Symmetry codes: (i) $x, y, z-1$; (ii) $x-1, y, z$.

for several days to give yellow crystals. The crystals were collected. Yield, $6 \mathrm{mg}$ (20\%). Anal. Found: C, 37.79; H, 3.50; $\mathrm{N}, 27.94 \%$. Calcd for $\mathrm{C}_{19} \mathrm{H}_{21} \mathrm{ClN}_{12} \mathrm{OZn}_{2}: \mathrm{C}, 38.06 ; \mathrm{H}, 3.53 ; \mathrm{N}$, $28.03 \%$. IR $\left(\mathrm{KBr}, \mathrm{cm}^{-1}\right): v\left(\mathrm{~N}_{3}\right) 2077, v(\mathrm{C}=\mathrm{N}) 1626$.

A preliminary examination was made, and data were collected on a Bruker CCD X-ray diffractometer (SMART APEX) using graphite-monochromated Mo- $K \alpha$ radiation. Crystal data and details concerning the data collection are given in Table 1. The structure was solved by an intrinsic phasing method and refined by full-matrix least-squares methods. The fifth ligand of each zinc atom was found to be occupied by chloride ion and azido ions with half occupancy. The hydrogen atoms were inserted at their calculated positions, and fixed there. All of the calculations were carried out on a Windows 7 Core i7 computer utilizing the SHELXT-2014/4 and SHELXL-2014/7. ${ }^{8}$ Crystallographic data have been deposited with Cambridge Crystallographic Data Centre (Deposit numbers CCDC-1845621). Copies of the data can be obtained free of charge via http://www.ccdc.cam.ac.uk/ conts/retrieving.html (or from the Cambridge Crystallographic Data Centre, 12, Union Road, Cambridge, CB2 1EZ, UK; Fax, +44 1223 336033; e-mail, deposit@ccdc.cam.ac.uk).

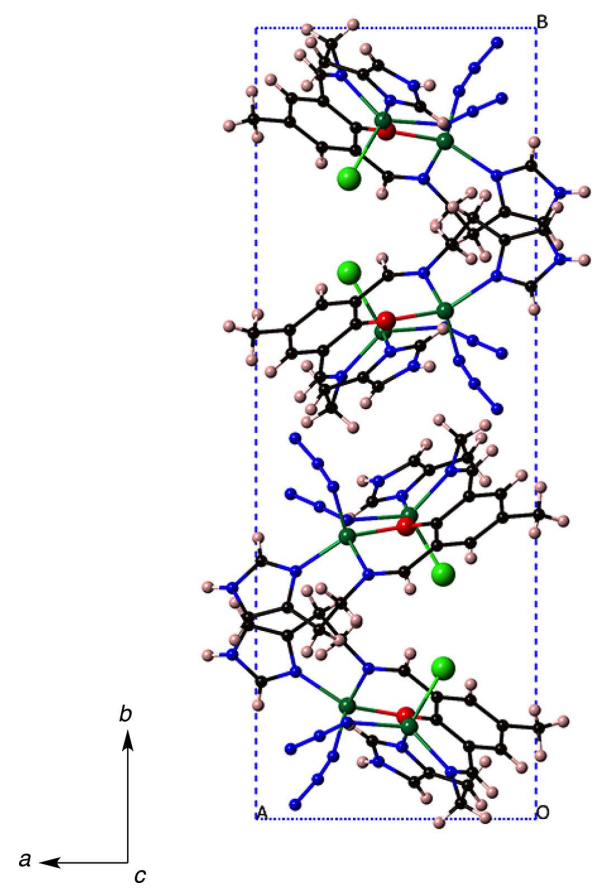

Fig. 3 Packing diagram of $\left[\mathrm{Zn}_{2}(\right.$ bimmp $\left.)\left(\mu-\mathrm{N}_{3}\right)\left(\mathrm{N}_{3}\right)(\mathrm{Cl})\right]$.

The asymmetric unit consists of one dinuclear molecule $\left[\mathrm{Zn}_{2}(\right.$ bimmp $\left.)\left(\mu-\mathrm{N}_{3}\right)\left(\mathrm{N}_{3}\right)(\mathrm{Cl})\right]$. The dinuclear molecule was drawn by the ORTEP program (Fig. 2). The $\mathrm{Zn} 1$...Zn2 distance is $3.3313(5) \AA$. In the dinuclear molecule, each zinc(II) atom is coordinated by $\mu$-phenolato-oxygen, imino-nitrogen, and imidazolyl-nitrogen atoms of bimmp ${ }^{-}$ligand with $\mathrm{Zn}-\mathrm{O}$ and $\mathrm{Zn}-\mathrm{N}$ distances of 2.0316(17)-2.1018(17) $\AA$ and 2.058(2)$2.099(2) \AA$, respectively, in a meridional fashion (Table 2). The fourth position of the coordination geometry is occupied by $\mu$ azido-nitrogen in an end-on fashion with different bond

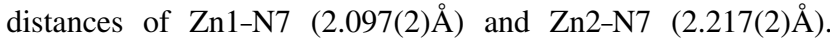
Besides these coordinations, other azido-nitrogen and chlorido atoms are coordinated to the $\mathrm{Zn} 1$ and $\mathrm{Zn} 2$ atoms with an occupancy factor of 0.5 to form a five-coordination. The $\tau$ values $^{9}$ of $\mathrm{Zn} 1$ and $\mathrm{Zn} 2$ are 0.597 and 0.008 , respectively, showing distorted trigonal-bipyramidal and square-pyramidal geometries, respectively. The $\mathrm{Zn}-\mathrm{O}$ and $\mathrm{Zn}-\mathrm{N}$ bond distances are within the range for five-coordinate zinc(II) complexes with related Schiff-base ligands. ${ }^{10,11}$ The chlorido ligands came from the reaction material, histamine dihydrochloride. In the crystal, the dinuclear molecule is loosely bound by hydrogen bonds between the imidazolyl nitrogen and the chlorido and azido ligands of the neighboring dinuclear molecules (Table 3, Fig. 3).

\section{Acknowledgements}

The present work was partially supported by Grants-in-Aid for Scientific Research No. 17K05820 from the Ministry of Education, Culture, Sports, Science and Technology and the MEXT-Supported Program for the Strategic Research Foundation at Private Universities, 2010 - 2014.

\section{References}

1. W. N. Lipscomb and N. Strater, Chem. Rev., 1996, 96, 
2375.

2. R. R. Gagné, M. W. McCool, and R. E. Marsh, Acta Cryst., 1980, B36, 2420.

3. J. Lorosch and W. Haase, Inorg. Chim. Acta, 1985, 108, 35.

4. M. Maekawa, S. Kitagawa, M. Munakata, and H. Masuda, Inorg. Chem., 1989, 28, 1904.

5. M. Mikuriya, Y. Hashimoto, and A. Kawamori, Chem. Lett., 1995, 1095.

6. M. Mikuriya, Y. Hashimoto, and S. Nakashima, Chem. Commun., 1996, 295.
7. M. Mikuriya, T. Fujii, T. Tokii, and A. Kawamori, Bull. Chem. Soc. Jpn., 1993, 66, 1675.

8. G. M. Sheldrick, Acta Cryst., 2015, C71, 3.

9. A. W. Addison, T. N. Rao, J. Reedijk, J. van Rijn, and G. C. Verschoor, J. Chem. Soc., Dalton Trans., 1984, 1349.

10. M. Mikuriya, S. Ikemi, and J.-W. Lim, Bull. Chem. Soc. Jpn., 2001, 74, 99.

11. M. Mikuriya, S. Ikemi, R. Nukada, and J.-W. Lim, Bull. Chem. Soc. Jpn., 2001, 74, 101. 